DOI 10.37882/2223-2974.2020.12.23

\title{
СРАВНИТЕЛЬНЫЙ АНАЛИЗ ПРАВОВОЙ БАЗЫ РЕГУЛИРОВАНИЯ ТЕХНОЛОГИЙ ИСКУССТВЕННОГО ИНТЕЛЛЕКТА В РОССИЙСКОЙ ФЕДЕРАЦИИ И В ЕС
}

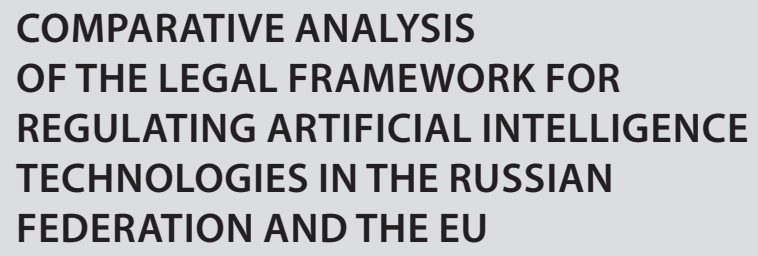

D. Kuzmin

Summary: Conducting a comparative analysis of the available approaches to the legal regulation of the use of artificial intelligence technologies in the Russian Federation and in the EU).

A comparative analysis of the legal regulation of the use of artificial intelligence in the Russian Federation and the EU is carried out, gaps in legal regulation are noted that contribute to the inhibition of legal and social development, the formation of the legal mentality of citizens of Russia and the EU in relation to artificial intelligence technologies is indicated, ways of harmonizing the gaps of legal regulation are proposed). An acceleration of the development of legal regulation of artificial intelligence technologies is ensured by the recognition of such a conventional software with a special way of forming a computational algorithm for data processing, as well as the elimination of speculation about the possibility of the emergence of self-awareness in such a technology, while strengthening international dialogue. Thus, interaction with dynamic high-tech clusters of the United States, South Korea, China and the EU will allow the Russian Federation and the EU to accelerate the adoption of generally understood principles of regulation and law enforcement of such technology and at the same time create protection for any attempts to avoid responsibility for the man-made consequences of the activities of complex information and software and hardware devices.

Keywords: legal regulation, artificial intelligence, digitalization of the economy, digital inequality, information technology, digital transformation.

\section{Введение}

роведение сравнительного анализа правовой базы регулирования технологий искусственного интеллекта в Российской Федерации и в ЕС исполнено в настоящей работе по состоянию на май 2020 г. Базой для построения настоящего сравнительного анализа являются:

1. анализ правового регулирования использования искусственного интеллекта в ЕС [40];

2. анализ правового регулирования использования
Кузьмин Дмитрий Владимирович

ФГБОУ ВО «Всероссийский государственный университет юстичии (РПА Минюста России)», РФ, Москва,

dvkuzmin@gmail.com

Аннотация: Цель: проведение сравнительного анализа имеющихся подходов правового регулирования использования технологий искусственного интеллекта в Российской Федерации и в ЕС.

Результаты: проведен сравнительный анализ правового регулирования использования искусственного интеллекта в Российской Федерации и ЕС, отмечены пробелы правового регулирования, способствующие торможению правового и общественного развития, указано на формирование правового менталитета граждан России и ЕС в отношении технологий искусственного интеллекта, предложены пути гармонизации пробелов правового регулирования.

Выводы: ускорение развития правового регулирования технологий искусственного интеллекта обеспечивается признанием таковой обычным программным обеспечением с особенным способом формирования вычислительного алгоритма обработки данных, а также устранением спекуляций о возможностях возникновения самосознания у такой технологии, с одновременным усилением международного диалога. Так взаимодействие с динамичными высокотехнологичными кластерами США, Южной Кореи, Китая и ЕС позволит Российской Федерации и ЕС ускорить принятие общепонятных принципов регулирования и правоприменения такой технологии и одновременно создадут защиту для любых попыток избегания ответственности за техногенные последствия деятельности комплексных информационных и программно-аппаратных устройств.

Ключевые слова: правовое регулирование, искусственный интеллект, цифровизации экономики, цифровое неравенство, информационные технологии, цифровая трансформация.

искусственного интеллекта в Российской Федерации [41].

Вместе с тем необходимо отметить, что за истекший период в августе 2020 г. Правительством Российской Федерации приняты:

- Концепция развития регулирования отношений в сфере технологий искусственного интеллекта и робототехники до 2024 года [42];

- Федеральный проект «Искусственный интеллект» национальной программы «Цифровая экономика 
Российской Федерации».

В рамках концепции определены основные подходы по трансформации нормативного регулирования в России для применения технологий искусственного интеллекта с учетом соблюдения безопасности и прав граждан и государства. В частности, в Концепции отмечается, что обособленность использования систем искусственного интеллекта выражена в автономности их действия, а также неспособностью решать этические задачи или воспринимать нормы социальной деятельности. Одновременно Концепция смещает фокус нормотворческих усилий с привязки систем искусственного интеллекта к «большим данным» в сторону технологий роботизации, что является шагом по учету вопросов правового регулирования роботизации в сравнении с этапом их ассоциации с технологиями искусственного интеллекта, приходящимися в ЕС на период до 2018 года.

Реализация федерального проекта «Искусственный интеллект» выстраивается с учетом указанной Концепции, однако фокус проектной реализации нацелен на создание «дата-сетов» - наборов данных (в том числе «больших данных» и иных библиотек, и справочников), позволяющих эффективно применять центральное ядро системы искусственного интеллекта - нейросеть. Указанный подход является составной частью технократической повестки цифровизации государственного управления и народного хозяйства.

В части развития нормативного правового регулирования использования технологий искусственного интеллекта в ЕС необходимо отметить, что в ноябре - декабре 2020 г. запланировано начало обсуждения законодательных инициатив, направленных на регулирование вопросов управления данными, конкуренции на цифровом рынке, а также использования искусственного интеллекта [43]. Следует отметить, что в рамках принятых инициатив «мягкого права» ЕС до настоящего времени не определены основные пути развития нормотворчества использования систем и технологий искусственного интеллекта. В связи с отмеченным новая нормотворческая инициатива может стать ключевым моментом выбора путей развития по регулированию применения таких технологий.

Учитывая изложенное, актуальность проведения сравнительного анализа правовой базы регулирования технологий искусственного интеллекта в Российской Федерации и в ЕС в настоящее время возрастает по мере увеличения числа политических заявлений и практических шагов в рамках такого отраслевого развития, а также с учетом многопараметрической схожести в историческом, культурном, правовом и геополитическом аспектах.

\section{Сравнительный анализ правовой базы регулирования технологий искусственного интеммекта в Российской ФеАерации и в ЕС}

Необходимо отметить, что как Российская Федерация, так и Европейский Союз имеют национальные и ментальные особенности в области правоприменения и подготовки регулирующих актов. Такие особенности являются неотъемлемой частью исторического наследия в том числе систем крепостного права в Российской Империи и института вассалов в европейских странах. Также многообразный религиозный подход различных формаций христианства внес существенные отличия в социальное поведение населения.

В связи с указанным субъективная реальность гражданина России характеризуется современными мыслителями, как «европейца снаружи, азиата внутри», имея в виду довольно либеральную внешнюю форму при строго зарегулированном внутреннем содержании. Это не типично для современного европейца, социально-экономическая реальность которого плотно коррелирует с менталитетом североамериканцев. Также современными исследователями отмечается, что европейский гражданин строго законопослушен, что особенно явно выражено в социумах Германии, Швейцарии, Норвегии, Швеции, Финляндии, Франции и Великобритании, а также в странах Бенилюкса.

Как в Российской Федерации, так и в Европейском Союзе объединено множество народов, однако правовая природа России и ЕС разная в связи с тем, что института государственности у последнего до настоящего времени не установлено. Тем не менее при принятии законодательства в области делегированных полномочий утвержденные нормы имею прямое действие на всей территории стран - членов ЕС. В связи с отмеченным в рамках анализа подобных норм правовое регулирование имеет идентичную природу.

Однако в рамках проведенного исследования в части ЕС установлено, что полномочия государствами - членами Союза в области развития «высоких» технологий до настоящего времени не делегированы «центральным» органам надгосударственного управления - Европейской Комиссии и Парламенту. При этом последние имеют полномочия по принятию аналогичных стратегических документов и координации общеевропейского вектора правового и технологического развития.

Данное обстоятельство является ключевым отличием от процессов федерального регулирования правоприменения и подготовки нормативных актов в Российской Федерации. Одновременно необходимо принимать во внимание строгую законопослушность европейцев (особенно развитых стран - членов), что влечет буквали- 
зацию соблюдения законов. Указанный элемент менталитета в области правового регулирования сказывается решающим образом необходимостью многочисленного взвешивания проектируемых решений. Картина правового регулирования в России несколько иная, здесь имеют преимущество народные традиции и межличностные договоренности, как в странах Ближнего Востока и Азии, а также распространена убежденность, что если «норма плохая, то она нерабочая» и упорствовать на ее исполнении никто не будет.

Конечно, в крайнем выражении и тот и другой стереотипы правоприменения неприемлемы и понятно, что общество будет стремиться к взвешенной адекватной позиции, но в части стран ЕС «приведение властей к знаменателю» означает вылитые бидоны молока или выгруженные телеги навоза напротив Европарламента, а в России - тихое игнорирование, если отсутствуют убедительные принудительные механизмы (профинансированные зарубежными разведывательными службами митинги «продвинутой» молодежи во внимание не принимаются).

Общими чертами правового регулирования и государственного планирования в России и ЕС использования технологий искусственного интеллекта является избрание пути применения «мягкого» права. В случае с российским подходом это выражается немногочисленностью законодательной базы в части такой технологии, при этом европейский подход очень схож и выражается в принятии стратегий и «белых книг» рекомендательного характера. Обязывающим элементом этих документов является контрактная сторона вопроса на проведение научно-исследовательских работ, а также распространение государственных рекомендаций целенаправленно для заинтересованных субъектов правовых и экономических отношений: государственным корпорациям, отраслевым институтам развития или специализированным организациям. Таким образом правовое поле спецификации особенностей регулирования гражданских отношений с технологиями искусственного интеллекта фактически обеспечивается правовыми рамками взаимодействия человека со сложными машинами и механизмами, а также информационными технологиями.

Обращает на себя внимание и тот момент, что инициация обсуждения вопроса регулирования развития технологий искусственного интеллекта обеспечена и в России, и в ЕС силами заинтересованного бизнес-сообщества, к числу которого следует отнести и научно-исследовательские организации. Так, в Российской Федерации основная политическая инициатива принадлежит банковскому сектору и ведущим ВУЗам страны, а в ЕС - объединениям научных коллективов в том числе при институте стандартизации IEEE и ряда других значимых организаций.
Заметна также и тенденция плавной смены технической «начинки» повестки цифровизации и применения искусственного интеллекта в ЕС. Например, если в начале научных и организационно-правовых поисков (2014 - 2017 годы) превалирует отнесение технологий искусственного интеллекта к взаимосвязи с робототехникой, то в текущем периоде (2018 - 2020 годы) акцент смещается на взаимосвязь с «большими» данными. Эта тенденция неслучайна, поскольку подкреплена масштабированием и успешным применением проектов формата «умный город», позволяющих в режиме реального времени и предиктивно обслуживать такие социальные нужды, как мониторинг многолюдных улиц с установлением личности и предметов, регулирование транспортного трафика и проч. Аналогичные модели искусственного интеллекта вступают во взаимодействие с человеком при банковском обслуживании (программный робот с библиотекой сценариев и ответов заменяет фронт-часть колл-центра, сокращая нагрузку и издержки оплаты труда персоналу), обслуживании операторов мобильной связи, цифрового телевидения и прочих хозяйствующих субъектов. Указанная ситуация характерна и для российской повестки цифровизации, за исключением того, что в России превалирование темы «больших» данных изначально стало основным спутником темы искусственного интеллекта.

Таким образом, при решении клиентских вопросов взаимодействие осуществляется (по типовым ситуациям) программой, алгоритм которой содержит технологию искусственного интеллекта (нейросеть и библиотеки данных). Вместе с тем функционирование таких систем носит справочно-информационный характер, однако вербальное общение и достаточно динамичный диалог этого программного обеспечения у неопытных или пожилых клиентов создает иллюзию общения с человеком. При этом приведение пояснений о том, что общение происходит с виртуальным роботом, может вызывать раздражение по причине возникновения когнитивного диссонанса, вызванного высокой степенью человекоподобности интерфейса. Замечания клиентов по этому поводу приняты во внимание рядом указанных хозяйствующих субъектов, диалог скорректирован предупреждением об общении с роботом. Таким образом право человека осуществлять коммуникацию с себе подобными в настоящее время значительно деформировано в России и ЕС, однако решений по общему урегулированию такого вопроса в настоящее время не предусмотрено.

В области регулирования информационного пространства также имеются схожие с глобальной повесткой аспекты правоприменения в ЕС и России. Формирование и редактирование новостной информации, социальных сетей, публичных полемик активно сопровождается технологиями искусственного интеллекта. 
Так, при появлении деструктивных общественных тенденций задействуются специальные алгоритмы смещения общественного мнения - окна Овертона, - что позволяет погасить или изменить направленность опасной дискуссии, а также установить причины и источники ее распространения. Очевидно, что такой подход серьезно изменяет действующие журналистские нормы и принципы, поскольку работоспособность программного обеспечения несравнима с человеческими силами и информационный фокус личностных нужд нивелируется, с правовой стороны не обеспечивая реализацию интересов личности. Необходимо отметить, что указанные программные средства негласно применяются во всех развитых и развивающихся странах мира, однако ни в EC, ни в России правовое регулирование таких информационных деформаций не предусмотрено.

Дополнительным общим проблемным аспектом обоих макрорегионов является слабый контроль исполнения бюджетной дисциплины. Выражается эта особенность в ЕС и России несколько разными путями, но также имеются общие моменты. Так, например, федеральные усилия российского правительства направлены на задействование средств федерального бюджета, крупных государственных компаний и частных инвестиций (в меньшей степени), также и европейские усилия направлены на привлечение частных инвестиций в совокупности с надгосударственными. Каскад трансфертов средств имеет не менее 5 итераций: принятие государственного бюджета правительств, доведение лимитов главным государственным распорядителям, распределение лимитов организациям, уполномоченным для проведения конкурсного отбора кандидатов на получение помощи, перечисление средств головному исполнителю работ (интегратору), который вправе иметь неограниченную последовательность и число соисполнителей. Таким образом контроль реализации средств существенно ослабляется, дальнейшее применение полученных результатов остается малоизвестным или неизвестным.

По итогам проведенного сравнительного анализа на основе анализа правовых аспектов регулирования технологий применения искусственного интеллекта следует отметить, что общий путь применения мягкого правового регулирования достаточен для развития научно-технических заделов и его успешность зависит от целенаправленных инвестиций и исследований. Вместе с тем современная обстановка с приведенными примерами деформации правового поля граждан ставит актуальный вопрос необходимости проведения открытого диалога для урегулирования таких проблем.

\section{Зак^ючение}

В рамках настоящей работы проведен анализ нор- мативных правовых актов Российской Федерации и Европейского Союза в области правового регулирования применения технологий искусственного интеллекта. Использован сравнительно-исторический метод, а также проанализированы научно-исследовательские труды ведущих отечественных исследователей в области информационного права (Морозов А.В., Минбалеев А.В., Мохов А.И., Самойлова Н.В., Наумов В.Б., Полякова Т.А., Сафронов Е.Г., Рыбаков О.Ю., Тихонова С.В., Филатова Л.В., Шуйский В.П.,) [1 - 19], а также зарубежных ученых (Bernard Marr, Van Roy Vincent, Berryhill Jamie, Heang Kevin Kok, Clogher Rob, McBride Keegan, Buiten Miriam, Iphofen Ron, Kritikos Mihalis, Leslie David, Barrett Anthony, Baum Seth) [20 - 26]. Исследование раскрывает наличие объективных преимуществ у Российской Федерации в рамках перспектив регулирования таких правовых отношений, поскольку инициатива реализации «цифровой повестки» закреплена на год раньше по сравнению с ЕС. Вместе с тем существенными факторами, сдерживающими развитие применения искусственного интеллекта в народном хозяйстве, являются:

- локальные недостатки на фоне общей научнопромышленной востребованности, связанные с функционированием системообразующих государственных корпораций (опыт крайне низкой востребованности выделяемых субсидий и грантов в 2019 году при изначальной заявке Правительству Российской Федерации о такой потребности в 2018 году);

- бюрократизированная методика выделения и контроля освоения средств для обеспечения инвестирования в новейшие цифровые технологии (имеющиеся процедуры выделения субсидий влекут существенные временные издержки при подготовке и согласовании проектов соответствующих правительственных решений, обоснованности размеров выделяемых средств, требуют «ручного» урегулирования и минимум 2-месячного периода для подготовки распределения выделенных субсидий: необходимости содержания дополнительного бюрократического аппарата, разработки конкурсной документации, проведения конкурсов и приемки результатов);

- отсутствие имплементации рекомендаций по использованию Agile-подходов проектной реализации в сфере исполнения государственного заказа (Федеральным законом «О контрактной системе...» и реализующих его положения подзаконными актами предусматривается необходимость формирования «жестких» рамок технического задания государственных контрактов, при этом возможность внесения изменений, связанных с необходимостью тактико-технологического пересмотра поставленной задачи, может быть урегулирована по соглашению сторон лишь посредством заключения дополнительных со- 
глашений к такому контракту на сумму, не превышающую 10\% стоимости контракта. В связи с указанным распространена ситуация практической невостребованности результатов выполненных работ или оказанных услуг в связи с ограниченными возможностями управления поставленными задачами);

- недостаточно высокий уровень осведомленности населения России и ЕС о сущности правового регулирования и технических аспектов таких технологий (следует отметить, что в рамках федерального проекта «Кадры для цифровой экономики» национальной программы «Цифровая экономика Российской Федерации» предусматривается обеспечение покрытия спроса на специалистов в области цифровизации, программирования, администрирования информационных сетей и комплексов, архитекторов информационных систем, специалистов в области информационной безопасности, цифровизации государственного управления за счет цифровой трансформации и проч. Реализацией указанной задачи занимаются ведущие технические высшие учебные заведения и университеты);

- необходимость дальнейшего развития тактикотехнических приемов применения технологий искусственного интеллекта в области оказания государственных и муниципальных услуг (заимствование и найм перспективных и наиболее успешных частных цифровых платформ, урегулирование государственно-частного партнерства в рамках такого взаимодействия, реализация идеалов цифрового профиля гражданина, борьба за снижение материальных издержек бумажного документооборота путем автоматизации недоработанных участков, введение новых технологий идентификации и аутентификации личности с использованием комплексного синтезированного документо-биометрического подхода, ускорение введения усовершенствованных средств web-разработки и шифрования информации, позволяющих обеспечивать ускорение интерфейсного взаимодействия человека и компьютерной техники, а также ускоренное устранение методических недостатков прикладного уровня взаимодействия с учетом реализации принципа неприкосновенности банковских средств пользователя, подключенного к потребительскому интерфейсу);

- целесообразность ускоренного выведения в гражданский оборот наиболее эффективных технологий искусственного интеллекта, что отягощено экономически сложной ситуацией на фоне рецессивных тенденций и необходимости противодействия распространению новой коронавирусной инфекции, как на территории Российской Федерации, так и на территории стран - членов

\section{Европейского Союза.}

В части правового регулирования технологий искусственного интеллекта странами - членами ЕС и на надгосударственном уровне исследование показало на наличие существенных материальных ресурсов, предусмотренных для распределения при финансировании реализации задач в области развития указанной технологии. Амбициозные планы подкреплены инициативами институтов стандартизации, а также инвестиционным участием крупных международных корпораций в области информационных технологий.

Вместе с тем в качестве существенных недостатков правового регулирования технологий применения искусственного интеллекта в ЕС следует указать:

- исторически сложившееся разноскоростное развитие государств - членов ЕС [44], что не способствует ускоренному технологическому продвижению (страной-лидером ЕС по внедрению и совершенству преимущественного большинства технологий является Германия, за неq следуют Франция, Великобритания, Ирландия и Испания);

- национальные полномочия государств - членов ЕС в области реализации национальных политик развития и регулирования искусственного интеллекта не делегированы Европейской комиссии, что повлекло принятие каждым из государств членов ЕС отдельных стратегических программ и планов развития таких технологий;

- в части стран - членов с развитыми экономиками присутствуют жесткие объективные ограничения технологического развития (высокая стоимость найма и недостаток специалистов в области исследований и разработок искусственного интеллекта, сложные процедуры организации инвестирования, в части согласования проектов необходимых документов между «центральными органами» ЕС и правительствами государств - членов, высокая налоговая база, ориентированная на «социальную повестку», препятствующая улучшению инвестиционного климата);

- неоконченную процедуру кластеризации научно-технических сообществ, которые, например, в России являются членами или ассоциированными участниками государственных корпораций или фондов перспективных технологий развития (исторический период небольших исследовательских коллективов конца 90-х - начала 00-х годов не завершен по причине сложностей монетизации разрабатываемых продуктов в условиях высокой рыночной конкуренции с азиатскими партнерами. Так, авторскому коллективу проще и легче скооперироваться, создать и продать наработку, получив «быстрые» деньги, нежели погружаться в относительно неторопливое исследование с воз- 
можностями случайных открытий в ходе творческих поисков);

- большое количество документов рекомендательного характера, масса амбициозных заявлений и дискуссионных площадок на фоне отсутствия выраженных мер по таргетированию проблемных вопросов в области образования, уровня заработной платы, налогового бремени и проч.;

- невысокая активность проектной деятельности за истекший период 2020 года по сравнению с 2018 и 2019 годами, что также может быть связано с обострением «социальной повестки» ввиду пандемии;

- невысокий уровень правительственных инициатив в продвижении защиты «чувствительных» данных и встречное общественное неодобрение применения технологий «умного» скрининга мест большого скопления людей.

Подводя итог изложенного необходимо отметить, что путем ускорения развития правового регулирования технологий искусственного интеллекта посредством признания таковой обычным программным обеспечением с особенным способом формирования вычислитель- ного алгоритма обработки данных, а также устранения спекуляций о возможностях возникновения самосознания у такой технологии, с одновременным усилением международного диалога, например, с динамичными высокотехнологичными кластерами США, Южной Кореи и Китая позволят, как Российской Федерации, так и Европейскому Союзу ускорить принятие общепонятных принципов регулирования и правоприменения такой технологии. Вместе с тем создадут защиту для любых попыток избегания ответственности за техногенные последствия деятельности комплексных информационных и программно-аппаратных устройств.

Дополнительно следует отметить, что реализация государственных инициатив и программ подготовки кадров в области цифровой трансформации повлечет необходимость пересмотра работодателями стоимости найма подготовленных специалистов, поскольку глобализация рынка трудовых отношений создает очевидные риски перехода указанных специалистов в зарубежные компании, что негативно отразится на качестве отечественного человеческого капитала в последующей перспективе, а также не позволит организовывать обмен опытом начинающих и опытных специалистов.

\section{ЛИТЕРАТУРА}

1. Минбалеев А.В., Развитие российского законодательства об использовании беспилотного транспорта в условиях цифровой экономики // «Транспортное право и безопасность» Научный журнал Юридического института Российского университета транспорта (МИИТ): официальный сайт. URL: http://transsafety.ru/tpb/articles/2019/pdf/29/10_minbaleev.pdf;

2. Минбалеев A.В., Проблемы регулирования искусственного интеллекта // Научная Электронная Библиотека «Киберленинка»: официальный сайт. URL: https://cyberleninka.ru/article/n/problemy-regulirovaniya-iskusstvennogo-intellekta/viewer;

3. Минбалеев А.В. Воздействие конституционных прав и свобод человека и гражданина на развитие информационного права в условиях цифровизации современного общества // Научная электронная библиотека eLIBRARY.RU: официальный сайт. URL: https://www.elibrary.ru/item.asp?id =41143541;

4. Минбалеев A.В., Наумов В.Б., Полякова Т.А., Право в эпоху цифровой трансформации: в поисках решений // Научная электронная библиотека еLIBRARY. RU : официальный сайт. URL: https://cyberleninka.ru/ article/n/pravo-v-epohu-tsifrovoy-transformatsii-v-poiskah-resheniy/viewer;

5. Минбалеев А.В., Сафронов Е.Г, Правовая природа блокчейн // Научная Электронная Библиотека «Киберленинка» : официальный сайт. URL: https:// cyberleninka.ru/article/n/pravovaya-priroda-blokcheyn/viewer;

6. Минбалеев А.В. Система государственного управления в сфере интеллектуальной собственности // Научная Электронная Библиотека «Киберленинка» : официальный сайт. URL: https://cyberleninka.ru/article/n/sistema-gosudarstvennogo-upravleniya-v-sfere-intellektualnoy-sobstvennosti/viewer;

7. Минбалеев А.В. Принципы информационного права // НАУЧНАЯ ЭЛЕКТРОННАЯ БИБЛИОТЕКА «КИБЕРЛЕНИНКА» : Официальный сайт. URL: https:// cyberleninka.ru/article/n/printsipy-informatsionnogo-prava/viewer;

8. Минбалеев А.В., Доктрина информационной безопасности Российской Федерации: современное состояние и перспективы развития // Вестник УрФ0 «Безопасность в информационной сфере» : официальный сайт. URL: http://info-secur.ru/is_21/3(21)-2016_62-66.pdf;

9. Минбалеев А.В., Развитие правового регулирования информационного общества в России: стратегия и основные направления совершенствования законодательства / А.В. Минбалеев // Вестник УрФ0. Безопасность в информационной сфере. - 2017. - Том 3. - с. 43 - 49;

10. Морозов А.В. Правовое обеспечение информационной безопасности. - РПА Минюста России Москва, 2012. - 348 с.

11. Морозов А.В., Полякова Т.А. Организационно-правовое обеспечение информационной безопасности: монография. - РПА Минюста России Москва, 2013. - 385 с.;

12. Морозов А. В., Рыбаков 0.Ю., Тихонова С.В. Монография Правовая политика в цифровом мире: идеи, методология, доктрина Под ред. Рыбакова $0 . Ю$. Саратов, 2015, 23 п.л. - Норма М, 2015. - 555 с.;

13. 1Морозов А.В., Полякова Т.А., Филатова Л.В. Учебник Информационное право и информационная безопасность, 1 часть, 2016. - ВГУю Минюста России Москва, 2016. - 884 C.;

14. 1Морозов А.В., Полякова Т.А., Филатова Л.В. Учебник Информационное право и информационная безопасность для подготовки магистров и аспирантов // Информационное право. - 2015. - № 2(44). - с. 48 - 51;

15. Морозов А.В. Правовые проблемы обеспечения информационной безопасности образовательной среды // Вопросы правоведения. - 2018. - № 2. - с. 27 - 32; 
16. Морозов А.В. Регулирование рынка криптовалют (информационно-правовой аспект) // Вестник Московского университета. Серия 26. Государственный аудит. - 2019. - № 2. - с. 6 - 12;

17. Мохов А.И., Правовое регулирование использования компьютерных программ // Научная Электронная Библиотека «Киберленинка» : официальный сайт. URL: https://cyberleninka.ru/article/n/pravovoe-regulirovanie-ispolzovaniya-kompyuternyh-programm/ viewer;

18. Самойлова Н.В., Трансграничная передача персональных данных: проблемы правоприменения // Научная Электронная Библиотека «Киберленинка» : официальный сайт. URL: https://cyberleninka.ru/article/n/transgranichnaya-peredacha-personalnyh-dannyh-problemy-pravoprimeneniya/ viewer;

19. Шуйский В.П., Международная торговля в условиях цифровизации мировой экономики // Научная Электронная Библиотека «Киберленинка» : официальный сайт. URL: https://cyberleninka.ru/article/n/ mezhdunarodnaya-torgovlya-v-usloviyah-tsifrovizatsii-mirovoy-ekonomiki/viewer;

20. Bernard Marr, Why Everyone Must Get Ready For The 4th Industrial Revolution, 05.04.2016 // Журнал Forbes, [Эл.pec.], URL: https://www.forbes.com/ sites/ bernardmarr/2016/04/05/why-everyone-must-get-ready-for-4th-industrial-revolution/\#8fe9613f90b7;

21. Van Roy Vincent, JRC Technical Report. AI Watch. National strategies on Artificial Intelligence. A European perspective in 2019 // European Commission : официальный сайт. URL: https://publications.jrc.ec.europa.eu/repository/bitstream/JRC119974/national_strategies_on_artificial_intelligence_final_1.pdf;

22. Berryhill Jamie; Heang Kévin Kok; Clogher Rob; McBride Keegan (2019). Hello, World: Artificial Intelligence and its Use in the Public Sector (PDF). Paris: // OECD Observatory of Public Sector Innovation : официальный сайт. URL: https://oecd-opsi.org/wp-content/uploads/2019/11/Al-Report-Online.pdf;

23. Buiten Miriam (2019). «Towards Intelligent Regulation of Artificial Intelligence». // European Journal of Risk Regulation : официальный сайт. URL: https://www. researchgate.net/publication/339025965_Artificial_Intelligence_Regulation_A_Meta-Framework_for_Formulation_and_Governance;

24. Iphofen Ron; Kritikos Mihalis (2019-01-03). «Regulating artificial intelligence and robotics: ethics by design in a digital society // Taylor \& Francis Online : 0фициальный сайт. URL: https://www.tandfonline.com/doi/full/10.1080/ 21582041.2018.1563803?scroll=top\&needAccess=true;

25. Leslie David «Understanding artificial intelligence ethics and safety: A guide for the responsible design and implementation of Al systems in the public sector, 11.06.2019 // Zenodo : официальный сайт. URL: https://zenodo.org/record/ 3240529 \#.XtOVilUzbio;

26. Barrett Anthony M.; Baum Seth D. «A model of pathways to artificial superintelligence catastrophe for risk and decision analysis» 23.05.2016 // Cornell University : официальный сайт. URL: https://arxiv.org/ftp/arxiv/papers/1607/ 1607.07730.pdf;

27. Информационные материалы о национальной программе «Цифровая экономика Российской Федерации» // Правительство Российской Федерации: официальный сайт. URL: http://static.government.ru/media/files/3b1AsVA1v3VziZip5VzAY8RTcLEbdCct.pdf;

28. Upcoming Issues of EU Law: Compilation of In-Depth Analyses (Workshop 24 September 2014) [Electronic resource] // European Parliament [Site]. - // URL: http:// www.europarl.europa.eu/RegData/etudes/IDAN/2014/509987/IPOL_IDA(2014)509987(ANN01)_EN.pdf;

29. Нормативное регулирование цифровой среды // Минэкономразвития России: официальный сайт. URL: https://www.economy.gov.ru/material/ directions/ gosudarstvennoe_upravlenie/normativnoe_regulirovanie_cifrovoy_sredy/;

30. Медведев утвердил программу «Цифровая экономика», 31 июля 2017 г. // TACC: официальный сайт. URL: https://tass.ru/ekonomika/4451565

31. Shaping Europe's digital future // European Commission: официальный сайт. URL: https://ec.europa.eu/digital-single-market/en;

32. Хакеры взламывают видеоняни, терроризируют детей и выкладывают в сеть их фотографии, 20 января 2016 г. // Хабр: официальный сайт. URL: https:// habr.com/ru/ news/t/389381/;

33. EU Member States sign up to cooperate on Artificial Intelligence [Electronic resource] // European Commission [Site]. - // URL: https://ec.europa.eu/digital-singlemarket/en/news/eu-member-states-sign-cooperate-artificial-intelligence;

34. Перцептрон // Википедия. Свободная энциклопедия: официальный сайт. URL: https://ru.wikipedia.org/wiki/Перцептрон;

35. Центр стратегических разработок. «Вопросы регулирования цифровой экономики (Аналитический отчет)», с. 411 // Центр перспективных управленческих решений: официальный сайт. URL: https://cpur.ru/research_pdf/ Regulatory\%20issues\%20of\%20the\% 20digital\%20economy.pdf;

36. Knowledge for policy. Collaborations // European Commission : официальный сайт. URL: https://ec.europa.eu/knowledge4policy/ai-watch/collaborations_en;

37. Knowledge for policy. A timeline for visualising the Al history // European Commission: официальный сайт. URL: https://ec.europa.eu/knowledge4policy/ sites/ know4pol/files/timeline_0.png;

38. Shaping Europe's digital future. POLICY. Artificial Intelligence // European Commission: официальный сайт. URL: https://ec.europa.eu/digital-single-market/en/ artificial-intelligence;

39. Artificial Intelligence. European Perspective // European Commission: официальный сайт. URL: http://eu-commission.maps.arcgis.com/apps/Cascade/ index.html ?appid=f0403ce4dcb54d39bfbe4a7db71cd514.

40. Кузьмин Д.В. Анализ правового регулирования использования искусственного интеллекта в ЕС // Современная наука: актуальные проблемы теории и практики. Серия «Экономика и право». -2020. -№10. -С. 155-162 D0I 10.37882/2223-2974.2020.10.16.

41. Кузьмин Д.В. Анализ правового регулирования использования искусственного интеллекта в Российской Федерации // Современная наука: актуальные проблемы теории и практики. Серия «Экономика и право». -2020. -№10. -С. 163-171 D0I 10.37882/2223-2974.2020.10.17.

42. Распоряжение Правительства Российской Федерации от 19 августа 2020 г. № 2129-р.

43. New EU laws could erase its legacy of world-leading data protection // ACCESSNOW.ORG: официальный сайт. URL: https://www.accessnow.org/european-unionprivacy-legacy/ (дата обращения: 21.11.2020).

44. Mark Zuckerberg, «France already has one of the strongest Al research communities in the world», 05.03.2017 // Institute for Strategy \& Competitiveness: официальный сайт. URL: https://www.isc.hbs.edu/resources/courses/moc-course-at-harvard/Documents/pdf/student-projects/France\%20Al_2017.pdf (дата обращения 30.05.2020).

(с) Кузьмин Дмитрий Владимирович (dvkuzmin@gmail.com).

Журнал «Современная наука: актуальные проблемы теории и практики» 